\title{
Facebook Marketing and Its Influence on Consumer Purchase Behaviour in the Context of Bangladesh
}

\author{
Tohfa T. Mawa ${ }^{1} \quad$ Tanjila Hossain $^{2} \quad$ Md. Tanvir Rahman ${ }^{3} \quad$ Risala T. Khan ${ }^{1 *} \quad$ Taslima F. Shuva $^{4}$ \\ 1.Institute of Information Technology, Jahangirnagar University, Savar, Dhaka, Bangladesh \\ 2.Department of Accounting and Information Systems, Jahangirnagar University, Savar, Dhaka, Bangladesh \\ 3.Department of Information and Communication Technology, Mawlana Bhashani Science and Technology \\ University, Santosh, Tangail, Bangladesh \\ 4.Department of Computer Science and Engineering, Daffodil International University, Savar, Dhaka, \\ Bangladesh
}

\begin{abstract}
Facebook is a widely used social media platform where people usually spend a lot of time. Presently, it is considered a great way to outspread information globally through its artificial intelligence-based targeted control. As a result, Facebook also plays a vital role in the expansion of businesses due to its huge number of audiences around the universe. Nowadays to reach these customers very quickly and easily, businessmen around the world are utilizing Facebook as one of the best tools for marketing purposes. In Bangladesh, almost every person who possesses a smartphone or has internet accessibility uses Facebook as their primary social networking website. This frequent use of Facebook should have an influence on digital marketing. In this paper, we have tried to evaluate the influence of Facebook Marketing on customers' purchase behavior in the context of Bangladesh through an online survey and some face-to-face interviews. Secondary data are also collected from existing research, journals papers, online reports, and websites. After the analyses, it can be stated that Facebook Marketing, having a list of positive customer feedback, has a great influence on customer purchase behavior in Bangladesh. From the positive reviews of existing customers, it can also be said that the influence rate of new customers is very high as well.
\end{abstract}

Keywords:Facebook Marketing, Customers Buying Behaviour, Influence of Facebook Marketing, Digital Marketing

DOI: $10.7176 / \mathrm{EJBM} / 13-21-03$

Publication date: November $30^{\text {th }} 2021$

\section{Introduction}

Facebook is a social networking website where anyone can create a personal account very easily just by providing some basic information. On Facebook, people can share individual views, opinions, and express their emotions with friends. People can also connect with a lot of individuals using Facebook groups and pages. Here, a Facebook page can help to promote new or existing businesses or organizations and for discussion, Facebook groups are a great choice. Presently, it is almost impossible to find a person who is not familiar with Facebook. Even illiterate people are also using it, thanks to Facebook for being so user-friendly. Besides, the spread of the internet and the popularity of smartphones have changed the way of mass communication. People are now spending more time on social media websites than conventional hangouts and meetings. In this regard, Facebook is perceived as a great tool of communication that helps to keep in touch with friends and family members quite comfortably (Joo T. M. and Teng C. E. 2017). Even, for marketing or promotion of products and services people are preferring them on social media than the traditional approaches through television, radio, newspaper, billboard, and so on (Shawky S. et al. 2019). Nowadays people want to make the best use of smart devices and the internet for daily necessities. Apart from that, marketing communication through traditional mass media is very costly, and very difficult to measure the outcome (Kushwaha B.P. et al. 2020). In this regard, social media can provide a wide range of features and a method of direct conversation between buyers and sellers which was unthinkable previously (Huang L. et al. 2019; Mulyana A. et al. 2020). Therefore, marketers are trying to change the way of operation to make it more effective and get the best possible outcome by gaining consumers' attention. As a consequence, mass media are fading away and social media are gaining preference which results in the traditional advertising being moved towards digital media.

Social media has also become very vibrant in the era of the pandemic. During lockdowns and other restrictions, people are staying at home and surf social networking websites to pass their leisure time. Hence, online shopping has now become an imperative option as people are too busy with their lives, and also visiting the physical stores is risky during the pandemic (Ranjan A. et al. 2021). So, the customers are choosing Facebook as a tool for all necessary things such as social communication, online shopping, and so on. The consumers are also considering the social media platforms e.g., Facebook as a reliable source to get an idea about the products and/or services and compare among the available options, and even ask for suggestions. A study signifies that Facebook can be the stage for consumers to access better information about products and services, making it simple to connect with 
businesses through Facebook (Rahman M. A. et al. 2018). Facebook has also considered advertisements to be implemented in the eco-system. According to the news published on the official website of Facebook on 06 November 2007, Facebook ads was officially introduced for business to connect with users and target advertising to the exact audiences. At the launch of Facebook ads, more than 60 major brand partners including Coca-Cola Company, Microsoft, Sony, etc. were highlighted (Facebook 2021).

The number of digital marketing agencies has boomed over the past few years. Currently over 100 digital marketing agencies are grown up in Dhaka, Capital city of Bangladesh, only. This is a clear indication that digital marketing is having a good impact on the consumers' purchase decisions and businessmen are getting a good result from social media advertising or Facebook advertising (Huda S. S. M. et al. 2021). In this paper, we have tried to figure out the impact of Facebook Marketing on consumers' purchase decisions in the context of Bangladesh through online surveys and manual interviews. Numerical results demonstrate the great influence of Facebook Marketing on purchase decisions for Bangladeshi people.

Meanwhile, the rest of the paper is organized as follows: Section 2 presents an extensive review of literature, Section 3 focuses on the research methodology, then, data analysis and findings are presented in section 4 . Finally, conclusions are drawn in section 5.

\section{Literature Review}

In recent days, social media websites have become an essential tool not only for casual users but also for online buyers and sellers. People around the world are utilizing these websites for various purposes like spending leisure time, doing online business, promotional activities, social works, and so on. In Bangladesh, social media is extensively used and it has also become one of the most crucial components of marketing throughout the business environment (Hafez M. 2021). Among the various social media websites, Facebook is considered to be the largest and fastest-growing one in the world. The number of Facebook users in Bangladesh is also very high compared to the total population. According to "NapoleonCat", there are about 5 crores and to be exact 4,88,00,000 listed Facebook users up to June 2021 in Bangladesh (Facebook users in Bangladesh 2021). From another statistical website "StatCounter", among the total number of social media users in Bangladesh up to June 2021, about 89.12\% are on Facebook. The rest of the users are about $6.25 \%$ on YouTube and $4.63 \%$ on others comprising $1.42 \%$ on Pinterest, $1.26 \%$ on Twitter, $1.22 \%$ on LinkedIn, and $0.44 \%$ on Instagram (Social Media Stats Bangladesh 2021). Facebook can help to connect with numerous customers and deliver key specifications of the products, business information, services, event information to the target group. According to Broeck et al., Facebook is the most effective tool for the personalized promotion of products (Broeck E.V. et al. 2020). Marketers can design and develop strategies and advertising materials based on individual groups, age, sex, etc. Facebook has also been adopted by almost all the big companies. According to Facebook, there are about three million businesses from all over the world that actively advertise on Facebook (Facebook For Business 2021).

Previously marketers choose mass media for product advertising to create awareness and develop product preference among customers. But Facebook has altered the way of advertising. With the arrival of social media, traditional media such as television and newspaper have lost exclusive view ship and readership. The speed of online communication and large information sources make the traditional media less relevant. Furthermore, marketing professionals quickly realized the influence of social media in terms of individualized sections, shopping experience, convenience, and large information search (Frandsen M. et al. 2016; Jain A. 2021; Martins A. 2020). Here, Facebook can be the best tool for targeting specific customers through its paid campaigns as most of the information of users is available. The audiences can be easily divided according to the domain of the business which is an extremely important tool for companies to influence customer decision-making while online shopping (Trang T. P. 2017). With 349 survey responses, Zhu et al. conducted research on personalized advertisements and purchase intentions on social media. They have found these ads significantly contribute to higher purchase intentions (Zhu Y. et al. 2021). Another study by McClure and Seock states that the social media page with quality content of a brand has a great impact on a consumer's involvement in it which in turn influences future purchases from the same brand (McClure C. and Seock Y. 2020). Apart from these, there was a list of research conducted in recent years in order to find the impact of social media marketing on consumers' purchase intention where most of the result shows a significant outcome (Dabbous A. and Barakat K. A. 2020; Erlangga H. et al. 2021; Gupta S. et al. 2021; Park J. et al. 2021; Tran L. T. T. 2020; Weismueller J. et al. 2020). According to the circumstances stated above, presence in a social media channel is of paramount importance for companies. If the consumers failed to find enough information about the products they are looking to buy, they may revert to other substitutes who have a social media presence.

A study conducted in February 2021 by Pew Research Center has stated that 84\% of young adults aged 1829 are more likely to use social media (Pew Research Center 2021). In this new generation, young adults like to get information about new products even before the product launch. This is why renowned brands like Apple, Samsung, Google are releasing teasers before launching products to create hype in the market. According to Hubspot, there is about 71\% likelihood of purchase if the products are referred on social media (Ewing M. 2019). 
Forbes also cited that $81 \%$ of the customers purchasing decisions are influenced by the posts shared by their friends or family members (Ahmed M. 2021). When anyone from friends or family members purchase a product and share positive feedback, it creates a very good impression which triggers the buying decision from the same seller afterward. This research backed nicely to online advertising by showing a very positive result of online business. Considering the aforementioned facts, it is indicating a bright future of online business with digital marketing.

\section{Research Methodology}

\subsection{Objectives of the Study}

The objective of the study is to examine the impact of Facebook marketing on consumer purchase behavior in Bangladesh.

\subsection{Methodology}

The study is qualitative in nature and a survey based on a structured questionnaire was conducted to achieve the objective of the research. An online questionnaire using Google form has been developed to survey the respondents. The questionnaire was designed to collect information about the demographic profile of the respondents such as age, gender, occupation. In addition to this, various questions related to the frequency of using Facebook to purchase products and the types of products purchased, the problem of buying products through Facebook, factors affecting consumer behavior while Facebook marketing, etc. were asked from the respondents. Multiple choice questions, close-ended questions, Likert scale ranging from 1 to 5 rating has been included in the questionnaire.

\subsection{Sample Selection and Sample Size}

The data is collected from mainly Dhaka and Sylhet of Bangladesh. The convenience sampling method has been used and the questionnaire has been distributed randomly through social media like Facebook, Whatsapp, email to conduct this research work. A target of 51 respondents of different ages including both male and female. Simple charting and tabulation tools are used to recognize the behavior of the respondents for Facebook marketing.

Data for this survey has been collected mainly from two sources. These are:

- Primary Source
a. Online Survey
b. Online conversation with individual respondents
c. Face to Face conversation

- Secondary Source
a. Journals
b. Social Media websites
c. Existing research articles

The demographic profile of the respondents is shown in Table 1.

Table 1. Demographic profile of the respondents

\begin{tabular}{|c|c|c|}
\hline Type & Number of the Respondents & Percentage of total Sample \\
\hline Male & Gender & 41.2 \\
\hline Female & 30 & 58.8 \\
\hline & 21 & 19.6 \\
\hline $18-24$ & Age & 47.1 \\
\hline $25-31$ & 10 & 19.6 \\
\hline $32-40$ & 24 & 13.7 \\
\hline $41-50$ & 10 & 0 \\
\hline Above 50 & 7 & 66.67 \\
\hline & 0 & 33.33 \\
\hline Dhaka & Living Area & 11.8 \\
\hline Sylhet & 34 & 33.3 \\
\hline & 17 & 7.9 \\
\hline Govt. Job & Occupation & 41.2 \\
\hline Private Job & 6 & 3.9 \\
\hline Business & 17 & 1.9 \\
\hline Student & 4 & \\
\hline Homemaker & 21 & \\
\hline Others & 2 & \\
\hline
\end{tabular}




\section{Data Analysis and Findings}

4.1 Data Analysis

Data analysis has been accomplished through different descriptive statistics like frequency, percentage, and mean for all the collected data.

\subsubsection{Age of the Respondents}

In these demographic variables, several age groups of people have been included. There were 5 age groups started from 18 years and ended up to more than 50 years. According to figure 4.1, the respondents are mostly from the age group of 25-31 and then 18-24 years. This indicates that Facebook marketing has more impact on young adults. Marketers who have products for young adults should concentrate on Facebook marketing.
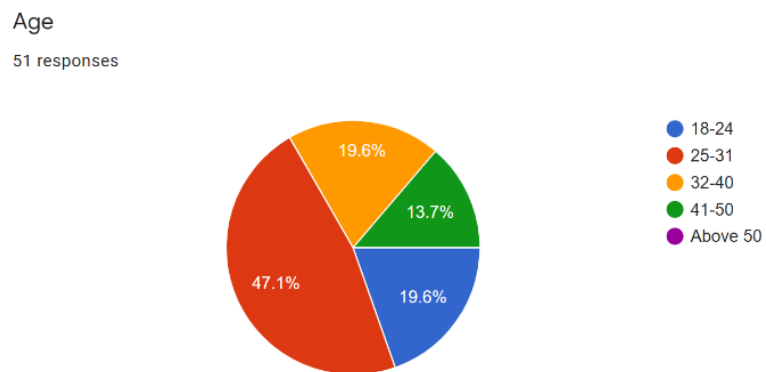

Figure 4.1 Age of the respondents

\subsubsection{Gender of the Respondents}

There was a total of 51 respondents, among them $58.8 \%$ were female and $41.2 \%$ were male shown in figure 4.2 . Though female respondents are a little higher, it can be said that it is a well-balanced survey among males and females.

$$
\begin{aligned}
& \text { Gender } \\
& 51 \text { responses }
\end{aligned}
$$

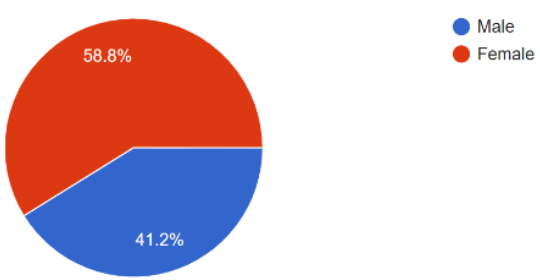

Figure 4.2 Gender of the respondents

\subsubsection{Occupation of the respondents}

This survey was conducted on people with various occupations to capture the profession-wise real scenario. Among the respondents mostly are students $41.2 \%$ and private job holders $33.3 \%$ and some from government job holders $11.8 \%$. There were some other respondents from homemakers and businesses and other professions shown in figure 4.3. Again, it is noticed that students and young adults are more prone to Facebook.

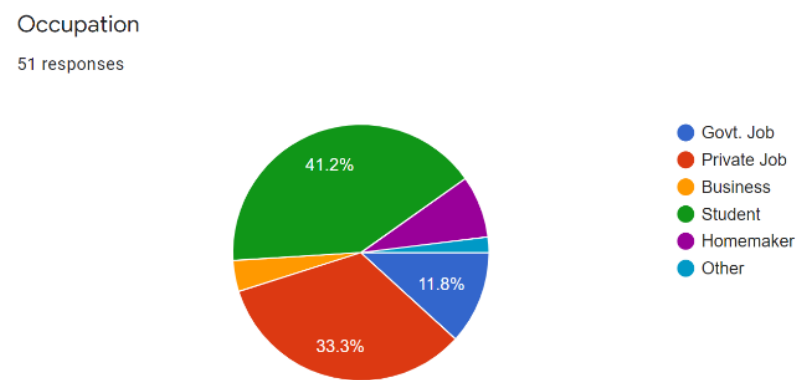

Figure 4.3 Occupation of the respondents 


\subsubsection{Social Media Preference}

From the responses, it is seen that the respondents use a list of social media websites but the responses are in favour of Facebook. It is about 48 respondents (94\%) prefer Facebook, 32 respondents $(62.7 \%)$ prefer YouTube, 18 respondents (35.3\%) prefer Instagram, 6 respondents (11.8\%) WhatsApp, and 2 respondents (3.9\%) prefers Twitter among the social media shown in figure 4.4 . We have also seen that today's digital marketing is mostly focusing on Facebook marketing and all the established companies have a strong presence on Facebook.

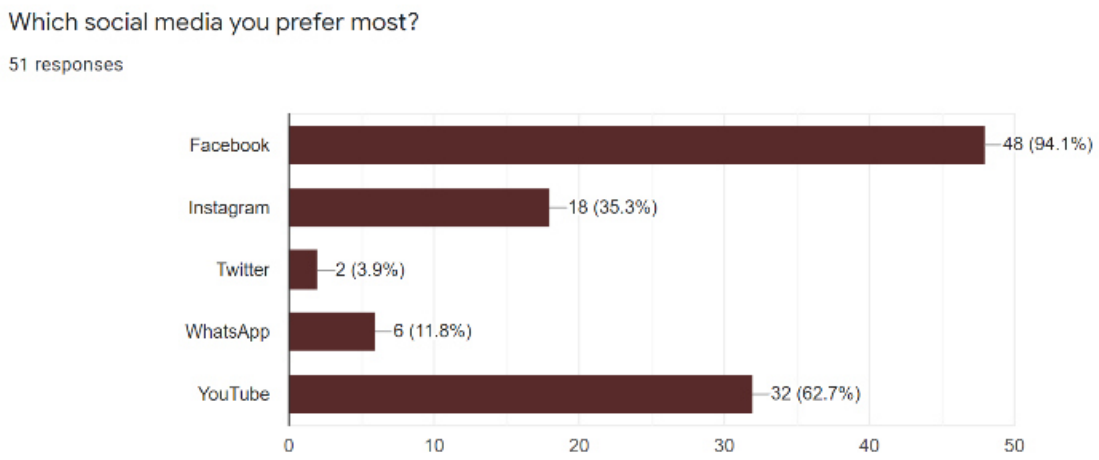

Figure 4.4 Social Media preference

\subsubsection{Frequency of Facebook usage}

Considering the huge preference for Facebook, it is time to evaluate the usage frequency of this website among the respondents. From figure 4.5 , it can be seen that $43.1 \%$ of the respondents use Facebook at least $1-2$ hours per day, $27.5 \%$ use $2-4$ hours, $19.6 \%$ use roughly 1 hour and $9.8 \%$ uses more than 4 hours per day.

\section{How frequently you use Facebook?}

51 responses

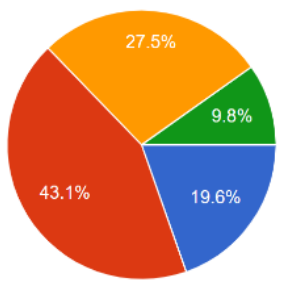

Figure 4.5 Frequency of Facebook usage

\subsubsection{Response on Purchasing from Online}

When asked about whether respondents buy online, $78.4 \%$ of the respondent answered "yes" and $17.6 \%$ answered "no" and 4\% was not sure about their response as shown in figure 4.6. This was a straightforward question. The aim of asking this question is to notice whether the respondents are buying things online or not. Presently, there are lots of delivery services working in the market. Because of the huge number of online orders these delivery services have also grown up.

Do you buy products/service from Facebook?

51 responses

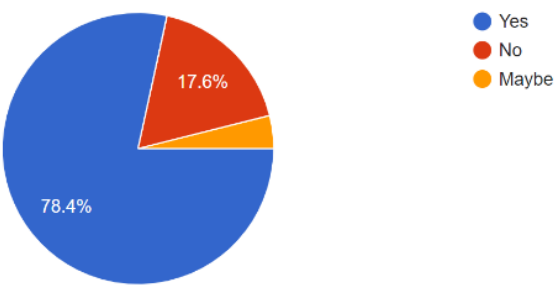

Figure 4.6 Response on purchasing from online 


\subsubsection{Types of Products or Services People usually buy from Online}

This question is to find out which type of products respondents mostly buy online. From the figure below, we can see that most of the respondents (66.7\%) are buying clothing items, $59.5 \%$ healthcare or skincare products, $42.9 \%$ groceries, $26.2 \%$ gadgets, and food \& beverage and the rest $16.7 \%$ usually buy home appliances. As most of the respondents are young adults and females, they are more prone to buy clothes and skincare products and gadgets online.

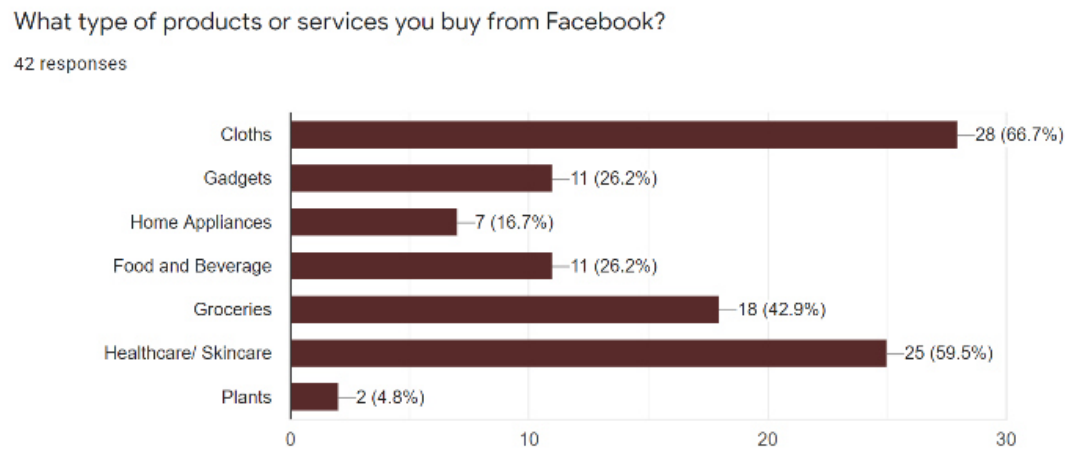

Figure 4.7 Types of Products of Services people usually buy from Online

\subsubsection{Frequency of Purchase from Online}

From figure 4.8 , it is visible that most of the respondents frequently purchase products online. The exact percentages are about $64 \%$ frequently, $10 \%$ monthly, $8 \%$ yearly, and the rest $18 \%$ never purchased online.
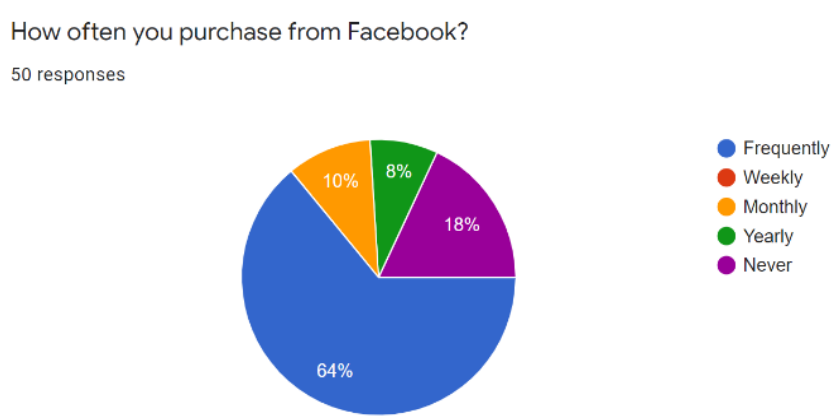

Figure 4.8 Frequency of purchase from Online

\subsubsection{Dependency on Facebook Reviews and Advertising Information}

The following figure 4.9 represents the fact that usually customers have faith in online reviews and feedbacks. The following question used a 5-point Likert scale ranging from 1 to 5 points from "Strongly disbelieve" to "Strongly Believe". About $48 \%$ of the respondents (24 out of 50 respondents) marked they "believe" in online reviews. About $24 \%$ of respondents (12 out of 50 respondents) marked they "nor believe nor disbelieve" on online reviews. $6 \%$ strongly believe and 6\% strongly disbelieve on online reviews and advertising. This data proves that the majority of the customers believe in online reviews and Facebook advertising. When asked face to face, respondents who marked the option "nor believe nor disbelieve", said that they have found faulty and paid reviews besides authentic reviews too. Though the risk of getting paid reviews remains, people believe in online reviews and advertising largely. 
How much you believe on Facebook reviews and information's?

50 responses

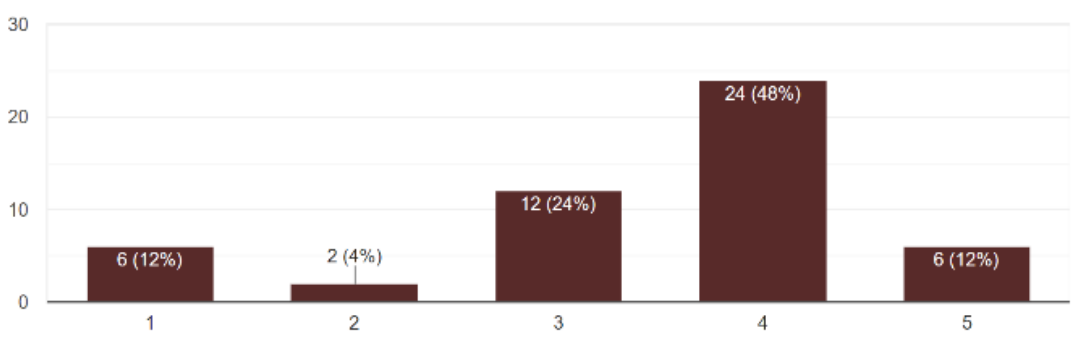

Figure 4.9 Dependency on Facebook Reviews and Advertising Information

\subsubsection{Influence of Facebook ads on Purchasing Behaviour}

Every business of today's world is trying to understand their customers' needs so that they can offer more personalized products to them or bring more innovation and attract more customers. The blessing of Facebook marketing has enabled businesses to collect real-time information from the consumers and act accordingly. In response to the question do you think Facebook ads influence your purchasing behaviour, $70 \%$ of respondents said yes, only $10 \%$ said no and $20 \%$ said they are not sure about is shown in the figure below. The marketers can use this opportunity to influence the target audience with proper Facebook marketing.
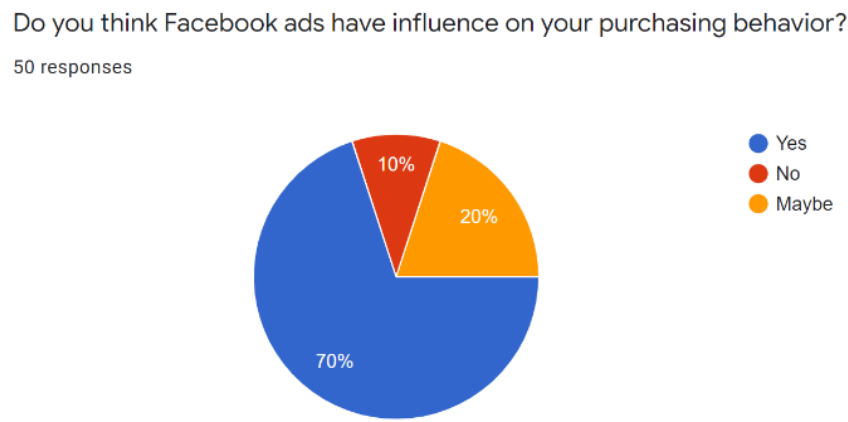

Figure 4.10 Influence of Facebook ads on Purchasing Behaviour

\subsubsection{Impact of Facebook Advertising on Customer Purchase Decision}

Facebook marketing has a great influence on customers purchasing decisions. This influence has a direct impact on product purchases. From figure 4.11, about $66.7 \%$ of customers have purchased products by watching ads on Facebook which may they have the intention to buy or may not. $21.6 \%$ of respondents never brought anything by watching Facebook advertise.
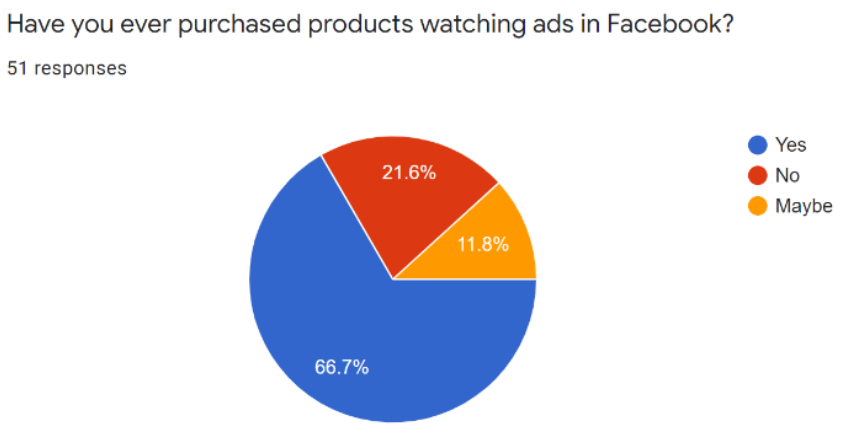

Figure 4.11 Impact of Facebook advertising on the Customer Purchase Decision

\subsubsection{Purchase Frequency from Facebook Advertising Influence}

From the responses given by respondents in this survey, we have seen that customers are influenced by Facebook advertising and lead to purchase. Promising data have also been found out from this question. $68 \%$ of respondents 
said that they have purchased multiple times by watching Facebook ads. When asked some of the respondents face to face regarding why they have purchased by watching Facebook ads, they have said that it was because of a promotional campaign, discounts, or they feel the need for the product after watching the advertisement. There are $22 \%$ of respondents who said that they have never purchased anything by watching Facebook ads.
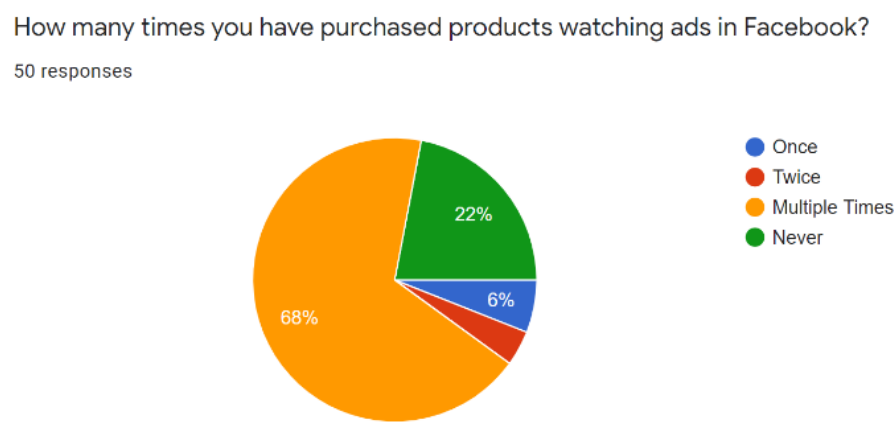

Multiple

Figure 4.12 Purchase Frequency from Facebook Advertising Influence

\subsubsection{Problems in Buying from Facebook}

Purchasing from online platforms has many advantages and disadvantages. In this survey, the most common problems faced by customers have been included. In this survey, most of the respondents have voted for clothing items that they have bought from Facebook, which is also reflected in this response. Almost 58\% said that the size variation is the main issue which mostly complies with clothing items. $38 \%$ said that quality, trust, and warranty guaranty issues are the second problem buying from online.

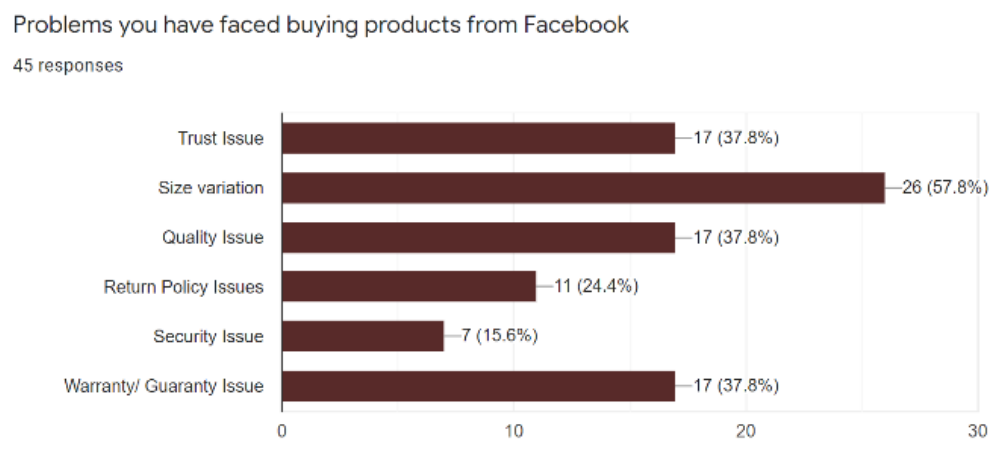

Figure 4.13 Problems in buying from Facebook

\subsubsection{Reason to buy Products from Facebook}

There may be specific reasons for individual customers to buy from Facebook. From this survey, 73.2\% said that home delivery is the main reason to buy online. Especially in 2020 during the COVID situation customers prefer not to visit a physical store. The traffic of Dhaka city is another reason to push customers to buy online. As the city dwellers can no longer tolerate traffic jams, many of them have decided to purchase products online as this is convenient and they can get the products sitting at home for the home delivery option offered by the businesses. Another $46 \%$ of the respondents said that it is easy and convenient to buy from Facebook. On online platforms, an unlimited number of products and their variants are seen. In physical stores, the number of product varieties is less as compared to online and difficult to explore. As a result, people don't find their desired product all the time.

Why do you buy products from Facebook?

41 responses

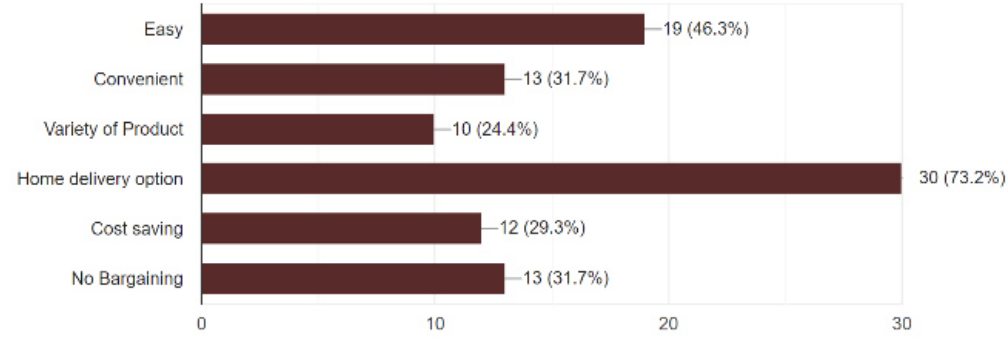

Figure 4.14 Reason to buy from Facebook 


\subsubsection{Frequency of Purchasing Products without a prior plan before watching Advertisements}

The following figure 4.15 represents the fact that about $68.8 \%$ of respondents have purchased a product that they had no plan to buy before watching the ad on online platforms. On the other hand, about $25.5 \%$ of respondents said they didn't buy. The rest of the respondents are not sure about their responses. The following data is significant as it shows that online ads can create a huge impact on consumers' purchase decisions.
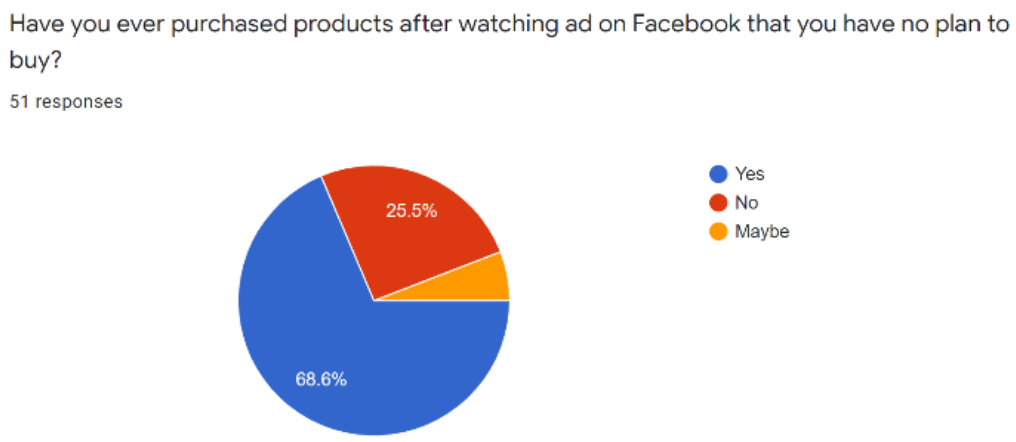

Figure 4.15 Frequency of Purchasing Products without a prior plan before watching Advertisements

\subsubsection{Frequency of Purchasing Products without a prior plan after watching Advertisements}

About $49 \%$ of respondents said they have brought products that they had no plan to buy after frequently watching Facebook ads. When asked face to face, respondents explained that it was due to a promotional offer. Eye-catching advertising also plays a vital role here. $25 \%$ of respondents said that they have never changed their minds by watching Facebook ads. Lastly, 13\% have brought only once and $11.1 \%$ brought twice that they had no plan to buy from online after watching advertisements.
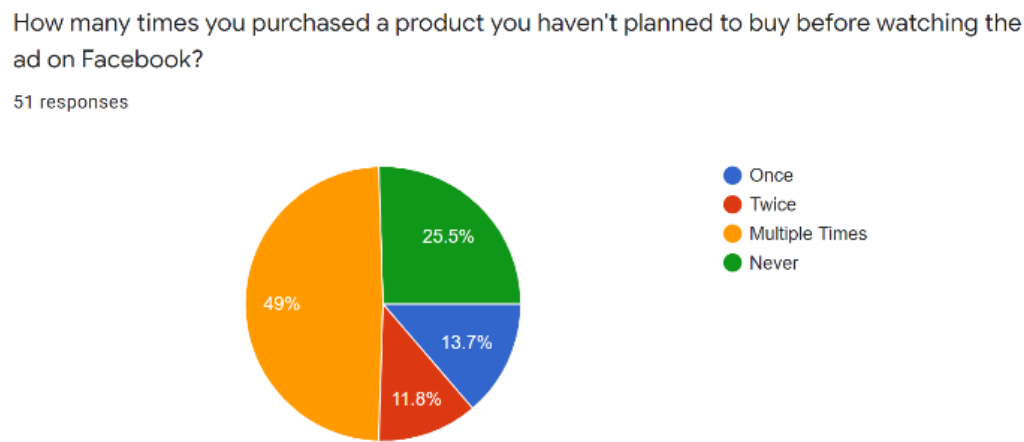

Figure 4.16 Frequency of Purchasing Products without a prior plan after watching Advertisements

\subsection{Findings from Interview \\ 4.2.1 Interview 1}

One of the face-to-face interviews also has been taken to evaluate the impact of Facebook marketing from the sellers' point of view. The interviewee was Mr. Jahidul Hasan, owner of "Purnima Sarees", Noor Mansion, Gawsia Super Market, Elephant Road, Dhaka, Bangladesh. From the answer to the question, have you got any response from Facebook advertising, he said that he has got a very good response from Facebook advertising. When asked how he has been benefited from Facebook advertising, he replied that he had only one cloth shop at the beginning. He added that after getting an idea about Facebook and YouTube marketing he started putting videos of clothes on Facebook and YouTube. He lastly finished by saying that a great response was coming from the social media websites and he has a total of seven shops right now.

\subsubsection{Interview 2}

Another interview was taken from the owner of "Ribana" Shop Mr. Wahiduzzaman Sadi. He said that at the starting of the business he only used Facebook marketing as he did not have any physical shop. He added that it took a long time to come to a successful stage. Now "Ribana" is a big brand. Many of the media artists are using Ribana's product. They also share their views on Facebook pages. Television actress Dilara Zaman Purnima is the Brand Ambassador of "Ribana" Shop. 


\section{Conclusion and Future Work}

5.1 Conclusion

After analysing the data, facts, and figures it can be concluded that Facebook marketing has a great impact on Bangladeshi customers. Although some of the studies conducted outside of Bangladesh have shown less impact of Facebook marketing, we have found that for the people aged between 18-31, Facebook marketing has a great influence in this study. When analysed professionally, students and private job holders are the most influenced customers through Facebook marketing. Here, home delivery options, convenience, and a variety of products are the main trigger points behind online shopping which were observed from this survey. Marketers should be very careful and specific about the tuning of customer targeting to have a great expansion of the business.

\subsection{Future Work}

The main focus of this study is to evaluate the influence of Facebook marketing and the customer segments that are most impacted by Facebook advertising. Further study should be conducted to compare other marketing tools with Facebook to get a clear understanding of which platform is having more impact on digital marketing in the context of Bangladesh.

\section{References}

Ahmed M., "Is Social Media the Biggest Influencer of Buying Decisions?”, May 2015. [Online]. Accessed on: 17 July 2021. Available: https://www.socialmediatoday.com/marketing/masroor/2015-05-28/social-mediabiggest-influencer-buying-decisions

Broeck E. V., Poels K., and Walrave M., "How do users evaluate personalized Facebook advertising? An analysis of consumer- and advertiser controlled factors", Qualitative Market Research, vol. 23, no. 2, pp. 309-327, 2020. doi: https://doi.org/10.1108/QMR-10-2018-0125

Dabbous A., Barakat K. A., "Bridging the online offline gap: Assessing the impact of brands' social network content quality on brand awareness and purchase intention", Journal of Retailing and Consumer Services, vol. 53, 2020. doi: https://doi.org/10.1016/j.jretconser.2019.101966.

Erlangga H., et al., "Effect Of Digital Marketing And Social Media On Purchase Intention Of Smes Food Products", Turkish Journal of Computer and Mathematics Education (TURCOMAT), vol. 12, no. 3, pp. $3672-$ 3678, 2021.

Ewing M., "71\% More Likely to Purchase Based on Social Media Referrals [Infographic]", 2019. [Online]. Accessed on: 17 July 2021. Available: https://blog.hubspot.com/blog/tabid/6307/bid/30239/71-More-Likelyto-Purchase-Based-on-Social-Media-Referrals-Infographic.aspx

Facebook, "Facebook Unveils Facebook Ads", Nov. 2007. [Online]. Accessed on: 07 July 2021. Available: https://about.fb.com/news/2007/11/facebook-unveils-facebook-ads

Facebook For Business, “Three Million Business Stories. What Yours?”, March 2016. [Online]. Accessed on: 16 July 2021. Available: https://www.facebook.com/business/news/3-million-advertisers

Frandsen M., Thow M., and Ferguson S. G., "The Effectiveness Of Social Media (Facebook) Compared With More Traditional Advertising Methods for Recruiting Eligible Participants To Health Research Studies: A Randomized, Controlled Clinical Trial", JMIR Research Protocols, vol. 5, no. 3, 2016. doi: https://doi.org/10.2196/resprot.5747

Gupta S., Nawaz N., Alfalah A. A., Naveed R. T., Muneer S., and Ahmad N., "The Relationship of CSR Communication on Social Media with Consumer Purchase Intention and Brand Admiration", Journal of Theoretical and Applied Electronic Commerce Research. vol. 16, no. 5, pp. 1217-1230, 2021. doi: https://doi.org/10.3390/jtaer16050068.

Hafez M., "The impact of social media marketing activities on brand equity in the banking sector in Bangladesh: the mediating role of brand love and brand trust", International Journal of Bank Marketing, 2021. doi: https://doi.org/10.1108/IJBM-02-2021-0067

Huang L., et al., "The communication role of social media in social marketing: a study of the community sustainability knowledge dissemination on LinkedIn and Twitter", Journal of Marketing Analytics, vol. 7, pp. 64-75, 2019. doi: https://doi.org/10.1057/s41270-019-00053-8

Huda S. S. M., et al., "Advertisement Practices in Bangladesh: Agency Perspectives", Handbook of Research on New Media Applications in Public Relations and Advertising, edited by Elif Esiyok, IGI Global, pp. 63-100, 2021. doi: https://doi.org/10.4018/978-1-7998-3201-0.ch005

Jain A., "Social Media vs Traditional Media and Their Impact on Brand Image Communication on Indian Millennials", Information Technology In Industry, vol.9, no.1, pp.1359-1373, 2021. doi: https://doi.org/10.17762/itii.v9i1.278

Joo T. M. and Teng C. E., "Impacts of Social Media (Facebook) on Human Communication and Relationships: A View on Behavioral Change and Social Unity", International Journal of Knowledge Content Development \& Technology, vol. 7, no. 4, pp. 27-50, 2017. doi: https://doi.org/10.5865/IJKCT.2017.7.4.027 
Kushwaha B. P., Singh R. K., Varghese N., and Singh V. N., "Integrating social media and digital media as new elements of integrated marketing communication for creating brand equity", Journal of Content, Community \& Communication, vol. 11, no. 6, pp. 52-64, 2020. doi: https://doi.org/10.31620/JCCC.06.20/06

Martins A., "Social Media gets faster responses from leaders than the Traditional Media does: A study of Twitter users in Nigeria", Journal of International DBA Studies, vol. 1, no. 001, 2020.

McClure C., Seock Y., "The role of involvement: Investigating the effect of brand's social media pages on consumer purchase intention", Journal of Retailing and Consumer Services, vol. 53, 2020. doi: https://doi.org/10.1016/j.jretconser.2019.101975.

Mulyana A., Rizki B., and Endi R., "ICT and social media as a marketing communication platform in facilitating social engagement in the digital era", International Journal of Innovation, Creativity and Change, vol. 13, no. 5, pp. 1-16, 2020.

Park J., Hyun H., Thavisay T., "A study of antecedents and outcomes of social media WOM towards luxury brand purchase intention", Journal of Retailing and Consumer Services, vol. 58, 2021. doi: https://doi.org/10.1016/j.jretconser.2020.102272.

Pew Research Center, "Social Media Fact Sheet", April 2021. [Online]. Accessed on: 17 July 2021. Available: https://www.pewresearch.org/internet/fact-sheet/social-media/

Rahman M. A., et al., "Consumer buying behavior towards online shopping: An empirical study on Dhaka city, Bangladesh", Cogent Business \& Management, vol. 5, no. 1, 2018. doi: https://doi.org/10.1080/23311975.2018.1514940

Ranjan A., Misra M., and Yadav J., "Online Shopping Behavior during COVID-19 Pandemic: An Indian Perspective", SSRN, 2021. doi: http://dx.doi.org/10.2139/ssrn.3874348

Shawky S., Kubacki K., Dietrich T., and Weaven S., "Using social media to create engagement: a social marketing review", Journal of Social Marketing, vol. 9, no. 2, pp. 204-224, 2019. doi: https://doi.org/10.1108/JSOCM05-2018-0046

“Social Media Stats Bangladesh", June 2021. [Online]. Accessed on: 17 July 2021, Available: https://gs.statcounter.com/social-media-stats/all/bangladesh

Tran L. T. T., "Online reviews and purchase intention: A cosmopolitanism perspective", Tourism Management Perspectives, vol. 35, 2020. doi: https://doi.org/10.1016/j.tmp.2020.100722.

Trang T. P., "Personalized ads on Facebook: An effective marketing tool for online marketers", Journal of Retailing and Consumer Services, vol. 39, pp. 230-242, 2017. doi: https://doi.org/10.1016/j.jretconser.2017.06.010.

Weismueller J., Harrigan P., Wang S., \& Soutar G. N., "Influencer Endorsements: How Advertising Disclosure and Source Credibility Affect Consumer Purchase Intention on Social Media”, Australasian Marketing Journal, vol. 28, no. 4, pp. 160-170, 2020. doi: https://doi.org/10.1016/j.ausmj.2020.03.002

Zhu Y., Kanjanamekanant K., "No trespassing: exploring privacy boundaries in personalized advertisement and its effects on ad attitude and purchase intentions on social media", Information \& Management, vol. 58, no. 2. 2021. doi: https://doi.org/10.1016/j.im.2020.103314.

Tohfa T. Mawa has completed her BSc in Computer Science and Engineering from The University of Asia Pacific in 2017. She is doing Masters in Information technology from Jahangirnagar University. Her research interest is artificial intelligence, computer graphics, animation, game science, digital marketing, e-commerce marketing, data science, etc.

Tanjila Hossain has completed her BBA. in Accounting \& Information Systems from the University of Dhaka in 2011, MBA. in Accounting \& Information Systems in 2012. She is doing MPhil from Jahangirnagar University in the field of Accountability and Governance of local government. She worked as a Lecturer in the Department of Business Administration, East-West University, Dhaka. She is now working as an Assistant professor at the Department of Accounting \& Information Systems, Jahangirnagar University, Savar, Dhaka, Bangladesh. Her research field is corporate social responsibility, social and environmental reporting, corporate governance, forensic accounting, GAAS, XBRL, etc.

Md. Tanvir Rahman was born in Meherpur, Bangladesh. He has received the B.Sc. (Hons) degree from Jahangirnagar University, Bangladesh, in 2013 and the M.Sc. degree from the same university in 2015, both in Information Technology. From 2015 to 2019, he was working as a Lecturer in the Department of Computer Science and Engineering, Daffodil International University, Dhaka, Bangladesh. From 2020 to till now he is working as a Lecturer in the Department of Information and Communication Technology, Mawlana Bhashani Science and Technology University, Bangladesh. His research interest includes but not limited to machine learning, software development, network security, etc. 
Risala Tasin Khan has completed her B.Sc. Hons. in Computer Science and Engineering from Jahangirnagar University, Savar, Dhaka in 2003, M.Sc. in Computer Science and Engineering in 2005. She has completed her Ph.D. from the same University in the field of the cognitive radio network. She worked as a Lecturer in the Department of Computer Science and Engineering, Daffodil International University, Dhaka. She is now working as a Professor at the Institute of Information Technology, Jahangirnagar University, Savar, Dhaka, Bangladesh. Her research field is spectrum sensing and the smart way of allocating channels in wireless communications using machine learning, network security, and various security issues in IoT.

Taslima Ferdaus Shuva was born in Dhaka, Bangladesh. She has completed her B.Sc. (Hons) in Information Technology from Jahangirnagar University, Bangladesh, in 2014 and the M.Sc. degree in Information Technology from the same university in 2016. She is currently working as a Sr. Lecturer in the Department of Computer Science and Engineering, Daffodil International University from 2016. Her research interest includes but not limited to network security, bioinformatics, and digital contact tracing techniques. 